\title{
Remote Controller Inverter 3 Phase Berbasis Mikrokontroller
}

\author{
Hadiyanto $^{1)}$, Saiful Ghozi ${ }^{2}$ \\ ${ }^{1)}$ Program Studi Teknik Elektronika, Politeknik Negeri Balikpapan \\ e-mail: hadiyanto@poltekba.ac.id \\ ${ }^{2)}$ Program Studi Teknik Elektronika, Politeknik Negeri Balikpapan
}

\begin{abstract}
Electrical machinery plays a very important in industry and in everyday life hari.Exsitasi or starting a means used by man to ignite and drive the electrical machinery tersebut.Beberapa way or starting exsitasi electrical machines taken by man to get a good efficiency power efficiency and torque efficiency. Thus it takes a piece of equipment that is capable of performing exsitasi electrical machines with a small power with torque besar.Inverter or more commonly known as VSD (Variable Speed Drive) is one option which is used in making exsitasi or starting the electric machines. The inverter is able to perform exsitasi electric machines both single phase and 3 phase with prefix absorbs very little power and have very besar.Pengasutan torque inverter done so fine that almost did not happen rebound flow and speed that can cause damage to the machines The electricity nor the couple or connecting circuits. In the world of industrial inverter controlled semi-automated and automated by the semi-automatic circuit pengendali.Pengendalian performed by a series of contactors and relays, while the control is automatically done by the PLC (Programmable Logic Control). Microcontroller can be used as a substitute for controlling performed by contactors, relays and PLC.Mikrokontroller able to control the start-stop, round forward and reverse rotation and control the motor rotation speed can be displayed in the display LCD (Liquid Cristal Display).
\end{abstract}

Keywords: inverter controller, remote controller, 3 phase inverter, microcontroller, inverter controllers

\begin{abstract}
Abstrak
Mesin-mesin listrik memegang peranan yang sangat penting dalam dunia industri maupun dalam kehidupan sehari-hari.Exsitasi atau pengasutan merupakan suatu cara yang digunakan oleh manusia untuk menyalakan dan menggerakan mesin-mesin listrik tersebut.Beberapa cara exsitasi atau pengasutan mesin-mesin listrik ditempuh oleh manusia untuk mendapatkan efisiensi baik efisiensi daya maupun efisiensi torsi. Dengan demikian dibutuhkan suatu peralatan yang mampu melakukan exsitasi mesin-mesin listrik dengan daya kecil dengan torsi besar.Inverter atau yang lebih sering dikenal dengan VSD (Variable Speed Drive) merupakan salah satu pilihan yang digunakan dalam melakukan exsitasi atau pengasutan pada mesin-mesin listrik. Inverter mampu melakukan exsitasi mesin-mesin listrik baik satu phase maupun 3 phase dengan menyerap daya awalan yang sangat sedikit dan mempunyai torsi yang sangat besar.Pengasutan yang dilakukan inverter sangat halus sehingga hampir tidak terjadi lonjakkan arus dan kecepatan yang dapat menimbulkan kerusakan pada mesin-mesin listrik tersebut maupun pada rangkaian couple atau penghubungnya. Dalam dunia industri inverter dikendalikan secara semi otomatis dan otomatis oleh rangkaian pengendali.Pengendalian dengan semi otomatis dilakukan oleh rangkaian kontaktor dan relay sedangkan pengendalian dengan otomatis dilakukan oleh PLC (Programable Logic Control). Mikrokontroller dapat digunakan sebagai pengganti pengendalian yang dilakukan oleh kontaktor, relay maupun PLC.Mikrokontroller mampu mengendalikan start-stop, putaran maju maupun putaran mundur dan mengendalikan kecepatan putaran motor yang dapat di tampilkan dalam display LCD (Liquid Cristal Display).
\end{abstract}

Kata Kunci: controller inverter, remote controller, inverter 3 phase, mikrokontroller, pengendali inverter 


\section{Pendahuluan}

Inverter 3 phase seringkali kita temui dalam sebuah industri baik industri dalam skala kecil maupun industri skala menengah dan besar. Inverter dalam sebuah industri digunakan untuk menyangga exsitasi satu atau lebih dari satu motor-motor 3 phase dalam satu rangkaian pengendalian. Inverter 3 phase digunakan dalam sebuah industri karena mempunyai karakteristik yang baik. Karakteristik tersebut meliputi proses startstop yang halus hampir-hampir tanpa lonjakan kecepatan, pengaturan kecepatan yang mudah tanpa harus melakukan tambahan rangkaian,daya start yang sangat rendah dengan torsi yang besar, dapat dilakukan pengendalian internal maupun dari eksternal baik untuk start-stop maupun kecepatan motor. Dalam industri pengendalian otomatis inverter yang umum dilakukan oleh PLC (Programable Logic Control).

Mikrokontroller dengan segenap karakteristik dan fungsinya mampu digunakan untuk menggantikan kedudukan PLC sebagai pengendali otomatis inverter. Bahkan mikrokontroller mampu dikolaborasikan dengan peralatan yang lain seperti display LCD (Liquid Cristal Display).LCD (Liquid Cristal Display) apabila di kolaborasikan dengan PLC butuh rangkain tambahan lain yang dapat menjembatani proses komunikasi datanya. Mikrokontroller dapat dilakukan pensettingan awal yang bervariasi sesuai dengan keinginan pengguna

\section{Metode Penelitian}

Dalam penelitian ini, penulis menggunakan beberapa metode penelitian, diantaranya studi literature, perencanaan dan perancangan hardware, serta perancangan software.

Dalam studi literatur ini peneliti mengumpulkan bahan-bahan literatur yang berhubungan dengan pengendalian inverter menggunakan mikrokontroller baik dari bukubuku diperpustakaan Politeknik Negeri Balikpapan maupun literatur dari internet yang berbentuk $e$-book.

Dalam mempermudah perancangan remote controller inverter berbasis mikrokontroller ini perancangan dibagi untuk tiap-tiap blok dengan urutan dari blok terdepan dilanjutkan dengan blok selanjutnya.

\section{Perancangan Tombol Kontrol Inverter}

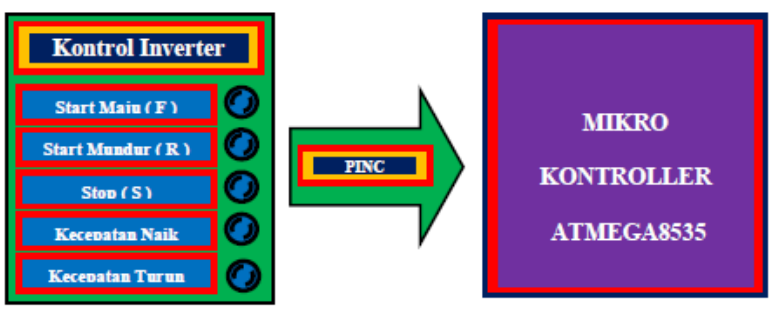

Gambar 4. Diagram Blok Tombol Kontrol Inverter
Kontrol Inverter

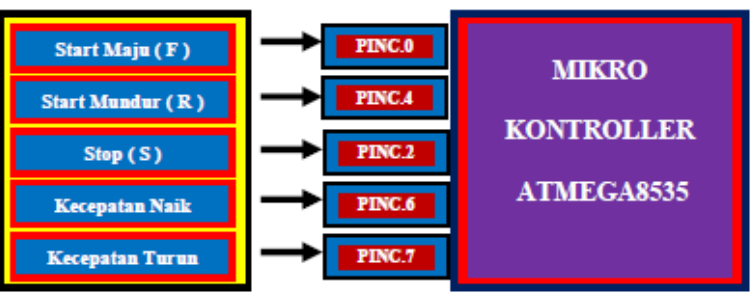

Gambar 5. Diagram Tombol Kontrol Inverter pada Mikrokontroller

Tombol pengendali Start Maju (F) di hubungkan pada Port $\mathrm{C}$ mikrokontroller Atmega8535 pada PIN C kaki no 0, tombol pengendali start mundur dihubungkan pada PIN C kaki no 4. Sedangkan tombol pengendali stop dihubungkan pada pin/kaki no 2. Pada bagian tombol pengendali kecepatan naik dihubungkan dengan mikrokontroller pada Port $\mathrm{C}$ kaki PIN $\mathrm{C}$ no 6. Tombol kecepatan turun dihubungkan pada kaki PIN C no 7.

\section{Perancangan Driver Relay}

Driver Relay dalam penelitiaan ini digunakan sebagai media penghubung antara mikrokontroller dengan inverter 3 phase.Driver relay merngkonversikan tegangan 5 Volt DC yang berasal dari mikrokontroller menjadi tegangan 24 Volt DC 
yang digunakan untuk mengendalikan startstop inverter 3 phase.

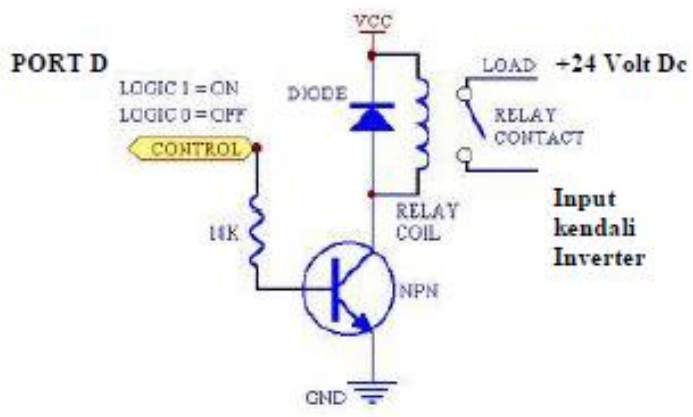

Gambar 6. Diagram Rangkaian Driver Relay Inverter pada Mikrokontroller

(Sumber: Paul scherzo, McGraw-Hill 2000)

\section{Perancangan Tampilan dengan LCD}

LCD (Liquid Crystal Display) adalah modul penampil yang banyak digunakan karena tampilannya menarik. LCD yang paling banyak digunakan saat ini ialah LCD M1632 refurbish karena harganya cukup murah. LCD M1632 merupakan modul LCD dengan tampilan 2x16 (2 barisx 16 kolom) dengan konsumsi daya rendah. Modul tersebut dilengkapi dengan mikrokontroler yang didesain khusus untuk mengendalikan LCD.

\section{Display $000102 \quad 06049506079899 \quad 10111213141516$

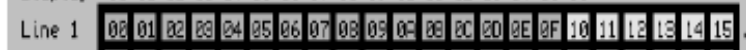

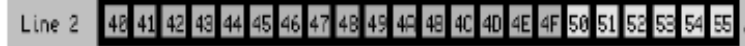

Gambar 7. Susunan Alamat pada LCD 16x2 (Sumber: Agfianto Eko Putra dan Dhani Nugraha)

Alamat awal karakter adalah $00 \mathrm{H}$ dan alamat akhirnya $39 \mathrm{H}$. karena itu dialamat awal di baris kedua dimulai dari $40 \mathrm{H}$. Jika menginginkan meletakkan suatu karakter pada baris ke-2 kolom pertama, maka alamat LCD harus diset pada alamat $40 \mathrm{H}$.

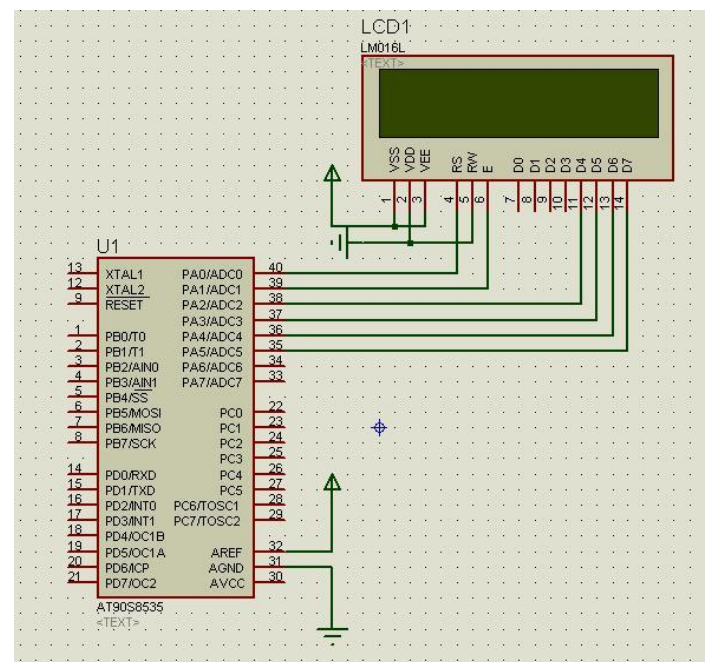

Gambar 8. Rangkain LCD pada Mikrokontroller Atmega 8535 (Sumber: Paul scherzo, McGraw-Hill 2000)

\section{Perancangan Software}

Sebuah mikrokontroller Atmega 8535 tidak dapat bekerja sesuai dengan yang kita inginkan apabila mikrokontroller Atmega 8535 tersebut tidak ditanamkan program yang berbentuk bilangan Hexadesimal pada chipnya. Program yang ditanamkan pada chip IC mikrokontroller Atmega 8535 tersebut berfungsi memberitahu apa yang harus dikerjakan mikrokontroller secara berurutan. Mikrokontroller Atmega 8535 akan menyimpan program yang telah di tanamkan padanya sampai batas waktu tertentu,sebab program yang telah ditanamkan pada sebuah chip mikrokontroller dapat dihapus secara elektrik dan diganti dengan program yang baru.

Mikrokontroller Atmega 8535 apabila program yang ditanamkan pada chipnya berganti maka fungsi dari mikrokontroller tersebut secara otomatis akan berubah sesuai dengan instruksi yang telah diprogramkan padanya. Instruksi-instruksi perangkat lunak tersebut berbeda-beda untuk masing-masing jenis mikrokontroller.Secara umum mikrokontroller hanya bisa mengenali nstruksi-intruksi tersebut sesuai dengan setting program pada mikrokontroller masing-masing. 


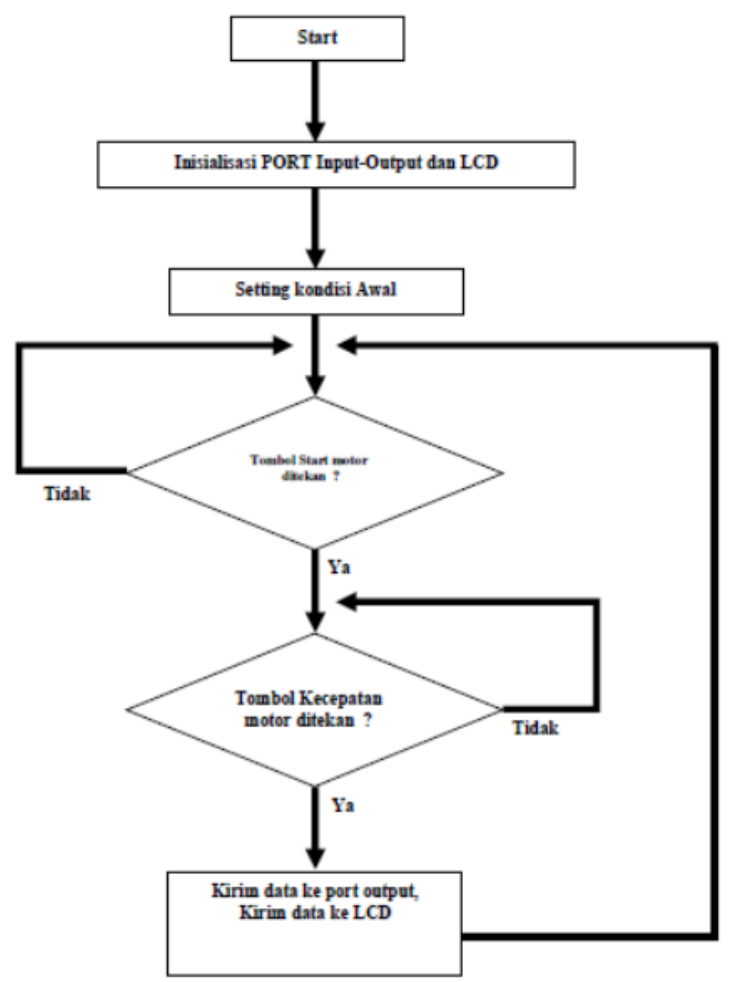

Gambar 9. Diagram Alur (flowchart) Remote Controller inverter

\section{Hasil Penelitian}

Setelah proses perancangan dan pembuatan sistem baik itu hardware maupun sofware selesai maka diadakan proses pengujian sistem.Tujuan dari pengujian sistem ini adalah untuk mengetahui apakah sistem dapat berfungsi sebagaimana mestinya atau tidak.Pengujian sistem dilakukan dengan 2 cara yaitu dengan simulasi dan pengujian keseluruhan sistem yang terdiri dari push button,modul driver relay,modul R2R Ladder ,modul sistem minimum mikrokontroller Atmega 8535, modul LCD dan inverter toshiba Vf-S11.Pengujian simulasi hanya menggunakan,modul Push button modul sistem minimum mikrokontroller Atmega8535,modul R2R Ladder,modul led dan modul LCD.

Berdasarkan hasil pengujian, akan diperoleh data mengenai pengendalian kecepatan motor untuk berbagai frekuensi dengan remote controller. Berikut data pengendalian tersebut:
Tabel 1. Tabel Pengendalian Kecepatan motor induksi 3 phase.

\begin{tabular}{|c|c|c|c|c|c|c|c|c|c|c|}
\hline \multirow{10}{*}{ Blok } & \multicolumn{10}{c|}{ KECEPATAN MOTOR INDUKSI 3 PHASE } \\
\hline \multirow{2}{*}{ Inverter } & $\mathbf{5}$ & $\mathbf{1 0}$ & $\mathbf{1 5}$ & $\mathbf{2 0}$ & $\mathbf{2 5}$ & $\mathbf{3 0}$ & $\mathbf{3 5}$ & $\mathbf{4 0}$ & $\mathbf{4 5}$ & $\mathbf{5 0}$ \\
& $\mathbf{H z}$ & $\mathbf{H z}$ & $\mathbf{H z}$ & $\mathbf{H z}$ & $\mathbf{H z}$ & $\mathbf{H z}$ & $\mathbf{H z}$ & $\mathbf{H z}$ & $\mathbf{H z}$ & $\mathbf{H z}$ \\
\hline \multirow{2}{*}{ LCD } & $\mathbf{5 , 8}$ & $\mathbf{1 0 , 2}$ & $\mathbf{1 6 , 1}$ & $\mathbf{2 1 , 0}$ & $\mathbf{2 5 , 7}$ & $\mathbf{2 9 , 8}$ & $\mathbf{3 5 , 2}$ & $\mathbf{4 0 , 0}$ & $\mathbf{4 5 , 1}$ & $\mathbf{5 0 , 0}$ \\
$\mathbf{H z}$ & $\mathbf{H z}$ & $\mathbf{H z}$ & $\mathbf{H z}$ & $\mathbf{H z}$ & $\mathbf{H z}$ & $\mathbf{H z}$ & $\mathbf{H z}$ & $\mathbf{H z}$ & $\mathbf{H z}$ \\
\hline $\begin{array}{c}\text { Teg VI* } \\
\text { (Volt) }\end{array}$ & $\mathbf{1 , 0 4}$ & $\mathbf{1 , 7 9}$ & $\mathbf{2 , 7 5}$ & $\mathbf{3 , 5 8}$ & $\mathbf{4 , 3 7}$ & $\mathbf{5 , 0 4}$ & $\mathbf{6 , 0 0}$ & $\mathbf{6 , 8 1}$ & $\mathbf{7 , 6 0}$ & $\mathbf{8 , 3 8}$ \\
\hline & Tegangan pada Vin kontrol kecepatan Inverter
\end{tabular}

Disamping itu, dari data hasil pengujian dilakukan analisa hasil,dimana dari analisa data pada hasil pengujian dapat dilihat sebagai berikut:

1. Pada pengendalian Start Maju ,Start Mundur dan Stop dapat dilakukan dengan hanya menekan tombol Start Maju,Start Mundur dan Stop.

2. Kecepatan Naik-Turun pada inverter hanya dapat dilakukan setelah tombol Start Maju atau Start Mundur ditekan.

3. SPEED pada tampilan LCD dan tampilan Inverter dapat disinkronkan sehingga tidak mempengaruhi kecepatan motor 3 phase.

4. Setelah motor induksi 3 phase berjalan atau running pada kecepatan tertentu,apabila tombol Stop ditekan tampilan pada LCD dan Inverter secara otomatis akan reset pada kecepatan $0 \mathrm{~Hz}$ sehingga motor induksi 3 phase akan stop dengan sendirinya.

\section{Kesimpulan}

Berdasarkan hasil yang telah dicapai ada beberapa kesimpulan yang perlu diperhatikan, diantaranya:

a. Dengan menggunakan fasilitasOutput/Input Mikrokontroller Atmega8535 dapat mengendalikan inverter dari tempat yang jauh.

b. Driver Relay hanya merupakan interface pengendali Start dan Stop inverter.

c. LCD yang terhubung dengan mikrokontroller digunakan sebagai tampilan kontrol atau pengendali menggantikan tampilan pada display inverter 3 phase bila inverter ditempatkan jauh dari ruang monitor pengendali. 
d. Putaran Maju dan Mundur dari motor induksi 3 phase dapat dikendalikan oleh mikrokontroller Atmega8535 dengan lebih sederhana .

e. Software AVRCodevision sangat membatu dalam pembuatan software,karena dengan software AVRCodevision mempersingkat waktu penulisan syntax software yang akan ditanamkan pada Chip Mikrokontroller Atmega8535.

\section{Saran}

Beberapa saran yang dapat diberikan dalam hubungannya dengan remote controller inverter berbasis mikrokontroller adalah:

a. Pengendalian inverter dari tempat yang jauh dari ruang monitor hendaknya tidak terlalu jauh karena kabel kontrol dan tegangan dc 5 Volt mudah terdistorsi atau interferensi sinyal lain.

b. Apabila pengendalian inverter dilakukan pada tempat yang jauh memungkinkan penggunaan metode / sistem wireless.

c. Sistem remote controller inverter berbasis mikrokontroller ini dapat dikembangkan dengan sistem terintegrasi pada DCS menggunakan komunikasi ModBus.

\section{Daftar Pustaka}

[1] Ardi Winoto,Mikrokontroller AVR Atmega8/32/16/8535 dan Pemrogramannya dengan bahasa $\mathrm{C}$ pada WinAVR,Informatika Bandung,2008.

[2] Tosvert VF-S11,Instruction

Manual,Industrial

Inverter,Toshiba Ver 108/109,2004.

[3] Paul scherz,Practical Electronic for Inventors,McGraw-Hill 2000.

[4] Agfianto Eko Putra dan Dhani Nugraha, Tutorial Pemrograman Mikrokontroler AVR denganAVR Studio dan WinAVR GCC (ATMega16/32/8535). 